\title{
Characterization of the Pituitary Gland Shape with MR Imaging
}

Shayma Hamed ${ }^{1 *}$, Ayad $\mathrm{CE}^{1}$, Alaa Ibrahim, ${ }^{2,4}$ Nisreen Hassan², Nmariq Abdbalrhman², Kawthar Moh. Sharif Abdulrhman ${ }^{3}$, Amna Mohamed Ahmed ${ }^{2}$

${ }^{1}$ Sudan University of science and technology, College of Medical Radiology Sciences, Khartoum, Sudan

${ }^{2}$ Department of Radiological Sciences, Al-Ghad International College, Tabouk, KSA

${ }^{3}$ Department of Radiological Sciences, Al-Ghad International College, Riyadh, KSA

${ }^{4}$ University of Medical Sciences and Technology, Khartoum, Sudan

DOI: $10.36347 /$ sjams.2020.v08i10.028

| Received: 06.10.2020 | Accepted: 20.10.2020 | Published: 26.10.2020

*Corresponding author: Shayma Hamed

Abstract

Magnetic Resonance Imaging (MRI) is the standard tool for the imaging of pituitary gland. The aim of the study was to characterize the shape of the pituitary gland in relation to age and sex. Methodology: A cross sectional prospective analytical study of the pituitary glands of Sudanese people, the data was collected from 301 Sudanese subjects (123 males' percent $40.9 \%$ and 178 females' percent 59.1\%) who underwent MRI examination for brain. Results the females gender are the big frequency distribution than males among study sample. The convex shape appear in females more than males in the age group 20-29 years old the concave shape appear in age group between 40-49 and 50-60, the flat appear in age group 20-29, partial empty in age group 30-39, the only one empty case appear in female in age group 40-49.Concolusion the pituitary gland can be accurately determined by using MRI and should be correlated with the patient's age and sex for further correlation.

Keywords: Pituitary gland, magnetic resonance imaging, age, gender.

Copyright $\odot$ (C) 2020 The Author(s): This is an open-access article distributed under the terms of the Creative Commons Attribution 4.0 International License (CC BY-NC 4.0) which permits unrestricted use, distribution, and reproduction in any medium for non-commercial use provided the original author and source are credited.

\section{INTRODUCTION}

The pituitary gland was first described anatomically by a Belgian scientist Andreas Vesalius in 1543.It is a small-sized gland with master functions; hence, its size and morphology have been a source of interest for many researchers. Sometimes in imaging, one takes a quick look at the contour of the superior surface of the pituitary gland or the size of the sella turcica as an indication or suggestion of enlargement of the gland. However, this would be misleading as the shape of the superior surface of the normal gland could either be flat, concave, or convex, depending on the hormonal status, age, sex, and even race of the individual. Also, the size of the bony sella is not a sensitive indicator of pituitary gland abnormality since an empty sella can lead to an enlarged fossa. Hence, there is a need for quantitative assessment. Magnetic resonance imaging (MRI) presently supersedes computerized tomography (CT) and plain radiographs in the investigation of the sella, parasellar, and suprasellar regions. MRI allows detailed visualization of the anterior and posterior lobes, pituitary infundibulum, optic chiasma, and other parasellar structures [1]

The coronal image is considered the best single view for imaging the pituitary gland, while the sagittal image best assesses the relationship of the midline structures [2].

The pituitary gland is the master endocrine gland of the human body. It controls other glands and secretes important hormones. Evaluation of pituitary size shape is the most important factors for the diagnosis of its pathology. Pituitary adenomas especially the microadenomas are diagnosed mainly with the information of pituitary size and its configuration. [3].

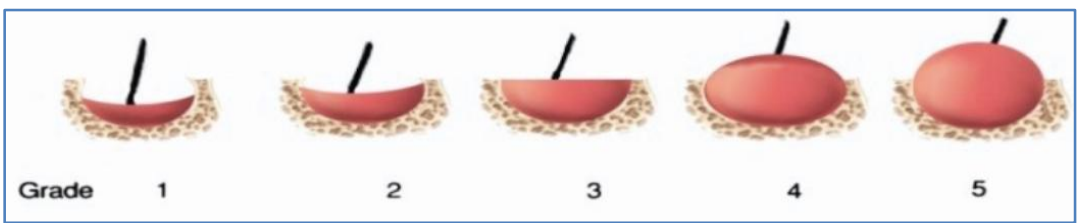

Fig-1: Scheme grade score for the shape evaluated in sagittal views 


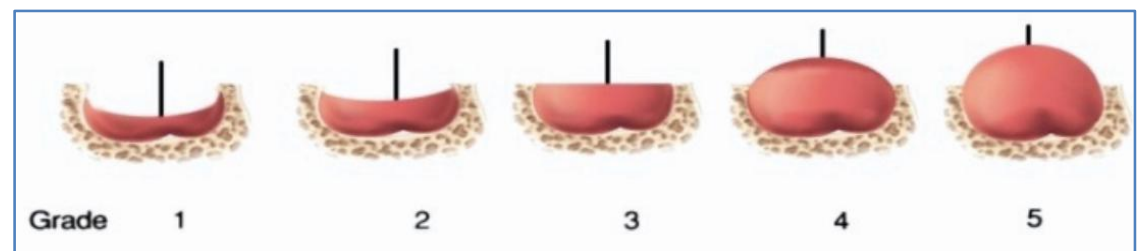

Fig-2: Scheme grade score for the shape evaluated in coronal views [4].

Grade 1 (G1) call "Concave", Grade 2 (G2) call "Concave" (different than G1, less than center of gland $2 \mathrm{~mm}$.), Grade 3 (G3) call "Flat", Grade 4 (G4) up more Grade 3 (but less than 2 mm.) call "Convex", Grade 5 (G5) call "Convex" (rather round shape). C. Keanninsiri1,

\section{Materials AND Methods}

A cross sectional prospective analytical study of the pituitary glands of Sudanese people, the data were collected from 301 Sudanese subjects (123 males' percent $40.9 \%$ and 178 females' percent $59.1 \%$ ) who underwent MRI examination for head at the Radiology and Imaging Department in the modern medical center during the period from 2015 to 2020 .
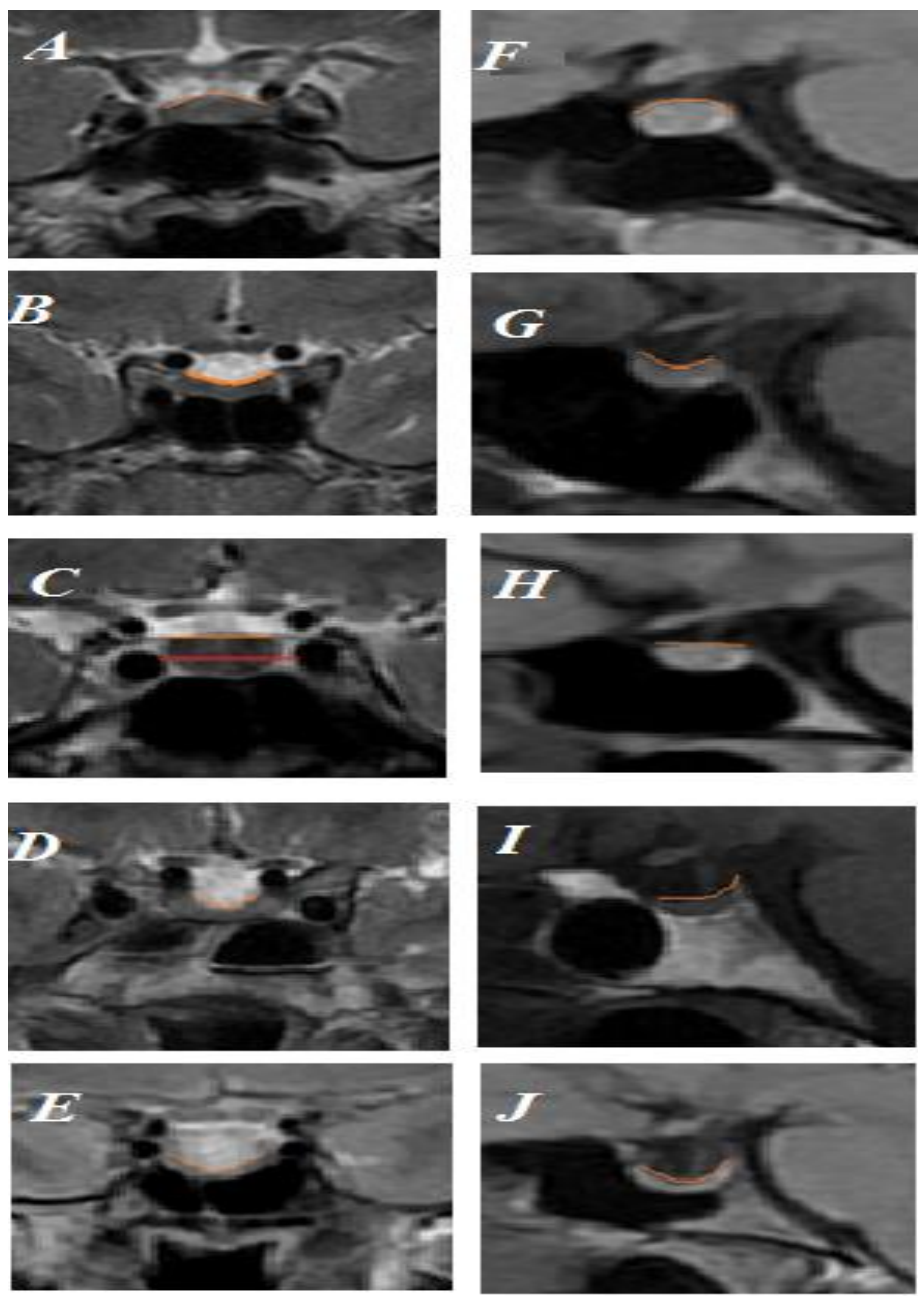

Fig-3: MR images shows the five shapes of pituitary gland convex, concave, flat, partial empty and empty sella respectively (A$D$ coronal sections )and(F-J) sagittal sections) 


\section{RESULTS}

In this current study, we analyzed the MRI scans of 301 patients of 20 years and older; $40.9 \%$ are males $(\mathrm{n}=123)$ and $59.1 \%$ females $(\mathrm{n}=178)$ represented in fig- 4 .

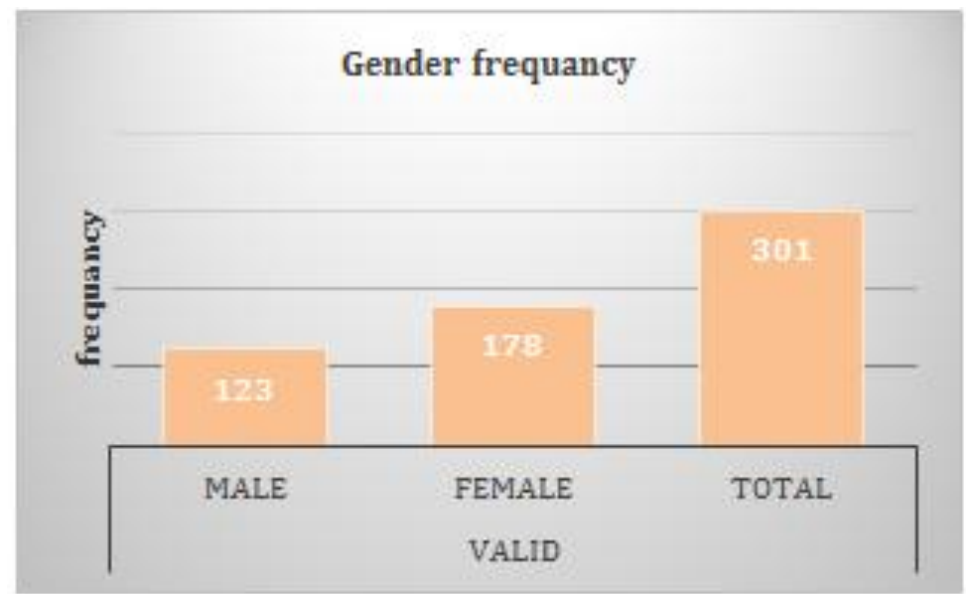

Fig-3: Distribution of participants' sex in the sample

The samples were divided according to gender into 4 age groups: 20-29 years, 30-39, 40-49 and 50-60
.Table 1 shows the frequency distribution crosstabulation.

Table-1: Distribution of participant's age groups and sex in the sample

\begin{tabular}{|l|l|l|l|l|}
\hline Age group & gender & count & frequency & percent \\
\hline \multirow{3}{*}{$20-29$} & male & 49 & 126 & 41.9 \\
\cline { 2 - 3 } $30-39$ & female & 77 & & \\
\hline $40-49$ & male & 26 & 63 & 20.9 \\
\cline { 2 - 3 } & female & 37 & 45 & \multirow{2}{*}{15.0} \\
\hline $50-60$ & male & 18 & 67 & 22.3 \\
\cline { 2 - 3 } & female & 27 & 301 & 100 \\
\hline total & male & 30 & 37 & \\
\cline { 2 - 3 } & female & 301 & & \\
\hline
\end{tabular}

Table-2: Shape of pituitary frequency distribution with the gender in the sample

\begin{tabular}{|c|c|c|c|c|c|}
\hline & \multicolumn{2}{|c|}{ Frequency } & \multirow{3}{*}{$\begin{array}{l}\text { Percent } \\
41.9\end{array}$} & \multirow{2}{*}{$\begin{array}{l}\text { Cumulative } \\
\text { Percent } \\
42.2\end{array}$} \\
\hline \multirow[t]{2}{*}{ Convex } & male & 50 & \multirow[t]{2}{*}{127} & & \\
\hline & female & 77 & & & \\
\hline \multirow[t]{2}{*}{ Concave } & male & 34 & \multirow[t]{2}{*}{80} & \multirow[t]{2}{*}{26.4} & \multirow[t]{2}{*}{68.8} \\
\hline & female & 46 & & & \\
\hline \multirow[t]{3}{*}{ Flat } & male & 25 & \multirow[t]{2}{*}{57} & \multirow[t]{2}{*}{18.8} & \multirow[t]{2}{*}{87.7} \\
\hline & female & 32 & & & \\
\hline & Total & \multicolumn{2}{|c|}{264} & & \\
\hline \multirow[t]{3}{*}{$\mathrm{PE}$} & male & 14 & \multirow[t]{2}{*}{36} & \multirow[t]{2}{*}{11.9} & \multirow[t]{2}{*}{99.7} \\
\hline & female & 22 & & & \\
\hline & Total & \multicolumn{2}{|c|}{300} & & \\
\hline \multirow[t]{2}{*}{$\mathrm{E}$} & male & 0 & \multirow[t]{2}{*}{1} & \multirow[t]{2}{*}{.3} & \multirow[t]{2}{*}{100.0} \\
\hline & female & 1 & & & \\
\hline \multicolumn{2}{|l|}{ total } & \multicolumn{2}{|c|}{301} & 100 & 100 \\
\hline
\end{tabular}


Table-3: Shape of pituitary frequency distribution within age group in the sample

\begin{tabular}{|c|c|c|c|c|c|c|c|c|}
\hline & \multicolumn{4}{|l|}{ Shape } & \multirow[b]{2}{*}{$\mathbf{E}$} & \multirow[t]{2}{*}{ Total } \\
\hline & & & convex & concave & flat & PE & & \\
\hline \multirow[t]{8}{*}{ age group } & \multirow[t]{2}{*}{$20-29$} & Count & 83 & 20 & 21 & 2 & 0 & 126 \\
\hline & & $\begin{array}{l}\% \text { of } \\
\text { Total }\end{array}$ & $27.7 \%$ & $6.7 \%$ & $7.0 \%$ & $0.7 \%$ & 0 & $42.0 \%$ \\
\hline & \multirow[t]{2}{*}{$30-39$} & Count & 17 & 18 & 13 & 15 & 0 & 63 \\
\hline & & $\begin{array}{l}\% \text { of } \\
\text { Total }\end{array}$ & $5.7 \%$ & $6.0 \%$ & $4.3 \%$ & $5.0 \%$ & 0 & $21.0 \%$ \\
\hline & \multirow[t]{2}{*}{$40-49$} & Count & 8 & 21 & 8 & 7 & 1 & 45 \\
\hline & & $\begin{array}{l}\% \text { of } \\
\text { Total }\end{array}$ & $2.7 \%$ & $7.0 \%$ & $2.7 \%$ & $2.3 \%$ & 0.3 & $15 \%$ \\
\hline & \multirow[t]{2}{*}{$50-60$} & Count & 19 & 21 & 15 & 12 & 0 & 67 \\
\hline & & $\begin{array}{l}\% \text { of } \\
\text { Total }\end{array}$ & $6.3 \%$ & $7.0 \%$ & $5.0 \%$ & $4.0 \%$ & 0 & $22 \%$ \\
\hline \multirow{2}{*}{\multicolumn{2}{|c|}{ Total }} & Count & 127 & 80 & 57 & 36 & 1 & 301 \\
\hline & & $\begin{array}{l}\% \text { of } \\
\text { Total }\end{array}$ & $41.9 \%$ & $26.4 \%$ & $18.8 \%$ & $11.9 \%$ & 0.3 & $100.0 \%$ \\
\hline
\end{tabular}

\section{DiscUSSION}

MRI usages are more effective than other imaging methods in visualizing the soft tissue like pituitary gland MR findings .This study focused mainly on the pituitary gland shape in relation with age and sex

In this study, the authors reported MRI data on measured the shape of pituitary gland in participants. There were $40.9 \%$ are males $(n=123)$ and $59.1 \%$ females $(n=178)$ represented in figure 3 their age was range from (20-60 years). Table 1 give the summary of the frequency distribution of sex with age group, the females gender are the big frequency distribution than males.Table 2 shape of pituitary frequency distribution, the shape of pituitary gland can affect some variable because of that we divided the cases according to the shape and analytic according to this divided in some relation variable. the total cases was 301 when excluded the one empty sella it will be 300 and when excluded the 36 partial empty the cases was be 264 the convex shape are the high frequency distributed and it appear in female more than male by $42.2 \%$ concave, flat, PE and $\mathrm{E}$ are the lower appear respectively.

Table 3 distribution the frequency of age group with pituitary shape, in age group 20-29 the convex shape appear in high frequency, concave appear in age group between 40-49 and 50-60, the flat appear in age group 20-29,PE in age group 30-39, the only one empty case appear in female in age group 40-49.

Previous studies have highlighted different changes in the shape of the upper surface of the pituitary gland at various stages of life, which also indicate the consequent change in hormonal levels [2] Results of the present study in agreement with previous studies.

Our result was that the convex shape was the high-frequency percentage $41.9 \%$ then concave in
$26.4 \%$, flat 18.8 , partial empty $11.9 \%$, empty sella by $0.3 \%$ respectively, the empty sella were seen in one patient in the age above 40 years we detect it in one female 43years old, these results were consistent with Samuel M. et al. [5], who detect that the larger gland was seen in the younger women and convex shape are the highest shape count in younger women. And the worth noting are these frequencies of shapes in our study are the same frequency distribution in the gender variable female and male, convex, concave, flat, PE, and empty sella respectively.

The convex shape appears higher frequently in the younger age group 20-29 then in the age group 50$60,30-39$ lastly in the age group 40-49. The concave shape appears more frequency in the age group 20-30, its frequency ware convergent in all age groups. the flat shape appears in more frequently in the age group 20 29 , partial empty was appear in the middle age group $30-39$ by a percentage of 5\%from total percentage of partial empty shape $11.9 \%$ and it appears in females more than male. The decline in the pituitary upper surface due to age may explain the process of aging similar finding was achieved by Tika $\mathrm{R}$ Lamichhane et al. [6], who reported that a higher frequency of convex upper border in female than in male in Nepalese population so that the flat shape is higher in male. Also, S. C. Sanjay et al. [7] noted that the gland was more convex globular in the younger age group in female $58.30 \%$, flat $3.1 \%$ then concave $11.10 \%$ and it was in the same order with age increase This is, however, contrary to the finding by Pratiksha Yadav1 et al. [8] who found that in all the age groups and both the sexes, the most common shape was flat, which was seen in $46 \%$ of people followed by convex in $31.2 \%$, concave shape in $22.8 \%$.

Also, C. Keanninsiri1 et al. [4], reported that the most frequency grade shape of the upper surface of the pituitary gland was the type of "flat" in male all age groups and in female groups except age group (11-20 
years), which higher frequency type of "convex". As we said depends on the upper surface for that it has a correlation between it and depth (height).

\section{CONCLUSiON}

The pituitary gland can be accurately determined by using MRI and should be correlated with the patient's age and sex for further correlation. The convex shape appears in high frequency in relation to other shapes IN THE FEMALES age group of 20-29 year old.

\section{REFERENCES}

1. Ibinaiye PO, Olarinoye-Akorede S, Kajogbola O, Bakari AG. Magnetic resonance imaging determination of normal pituitary gland dimensions in Zaria, Northwest Nigerian population. Journal of clinical imaging science. 2015;5.

2. Forbes K, Karis J, White WL. Imaging of the pituitary gland. Barrow quarterly. 2002;18:9-19.

3. Tsunoda A, Okuda O, Sato K. MR height of the pituitary gland as a function of age and sex: especially physiological hypertrophy in adolescence and in climacterium. American Journal of Neuroradiology. 1997 Mar 1;18(3):551-4.

4. Keanninsiri C, Cheiwvit P, Tritrakarn S, Thepamongkhol K, Santiprabhop J. Size and shape of the pituitary gland with MR imaging from newborn to 30 years: a study at siriraj hospital.

5. Wolpert SM, Molitch ME, Goldman JA, Wood JB. Size, shape, and appearance of the normal female pituitary gland. American journal of roentgenology. 1984 Aug 1;143(2):377-81.

6. Lamichhane TR, Pangeni S, Paudel S, Lamichhane HP. Age and gender related variations of pituitary gland size of healthy Nepalese people using magnetic resonance imaging. American Journal of Biomedical Engineering. 2015;5(4):130-5.

7. Sanjay SC, Subbaramaiah M, Jagannatha SR. Variation in size and shape of a normal adult female pituitary gland: A radiological study. Journal of Evolution of Medical and Dental Sciences. 2014 May 5;3(18):4934-40.

8. Yadav P, Singhal S, Chauhan S, Harit S. MRI evaluation of size and shape of normal pituitary gland: age and sex related changes. J Clin Diagn Res. 2017 Dec 1;11(12):TC01-4. 